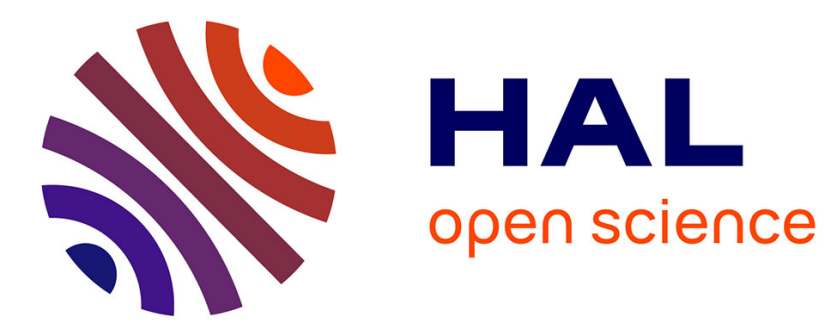

\title{
Different Er3+ environments in Mg-based nanoparticles-doped optical fibre preforms
}

Francesco d'Acapito, Wilfried Blanc, Bernard Dussardier

\section{To cite this version:}

Francesco d'Acapito, Wilfried Blanc, Bernard Dussardier. Different Er3+ environments in Mg-based nanoparticles-doped optical fibre preforms. Journal of Non-Crystalline Solids, 2014, 401, pp.50-53. 10.1016/j.jnoncrysol.2013.12.040 . hal-01053778

\section{HAL Id: hal-01053778 https://hal.science/hal-01053778}

Submitted on 1 Aug 2014

HAL is a multi-disciplinary open access archive for the deposit and dissemination of scientific research documents, whether they are published or not. The documents may come from teaching and research institutions in France or abroad, or from public or private research centers.
L'archive ouverte pluridisciplinaire HAL, est destinée au dépôt et à la diffusion de documents scientifiques de niveau recherche, publiés ou non, émanant des établissements d'enseignement et de recherche français ou étrangers, des laboratoires publics ou privés. 


\title{
Different $E r^{3+}$ environments in Mg-based nanoparticles-doped optical fibre preforms
}

\author{
F. d'Acapito ${ }^{a}$, W. Blanc ${ }^{b, *}$, B. Dussardier ${ }^{b}$ \\ ${ }^{a}$ CNR-IOM-OGG Grenoble \\ ${ }^{b}$ Univ. Nice Sophia Antipolis, CNRS, LPMC, UMR7336, 06100 Nice, France
}

\begin{abstract}
Developing new rare-earth ions-doped optical fibres for power amplifiers and lasers requires continuous improvements in fibres spectroscopic properties. To overcome some limitations inherent to silica glass, it is proposed to embed rareearth ions in dielectric nanoparticles. In this article we focus on the modifications of the $E r^{3+}$ ions spectroscopy in Mg-silicate nanoparticles doped into optical fiber preforms. Through EXAFS and fluorescence measurements, we demonstrate that different local environments are experienced by $E r^{3+}$ ions, attributed to the depolymerization of the phosphate network. These results gain insight into the tayloring of luminescence properties.
\end{abstract}

Keywords: silica, erbium, nanoparticles, magnesium, EXAFS, fluorescence, optical fiber

\section{Introduction}

Developing new rare-earth ions (RE)-doped optical fibres for power amplifiers and lasers requires continuous improvements in the fibres spectroscopic properties besides reduction in device size and economical efficiency. However, some potential applications of REdoped fibres suffer from limitations in terms of spectroscopic properties resulting from RE clustering or inappropriate local environment when they are inserted into silica. An interesting solution consists in using silica as a mechanical host and support of the fibre optical waveguide, and in embedding RE-ions within nanoparticles (NP) of appropriate composition and structure $[1,2,3]$.

The original route proposed by LPMC to obtain NP in fibres is based on the industrial MCVD (Modified Chemical Vapor Deposition) process. As silicate systems have a strong stable immiscibility when they contain divalent metal oxides, we take advantage of thermal treatments inherent to this process to obtain NP through the phase separation mechanism. Through this route, NP are grown in-situ within the material when alkalineearth ions $(\mathrm{Mg}, \mathrm{Ca}$ and $\mathrm{Sr}$ ) are incorporated into the fibre core $[4,5,6]$. In particular cases the effect of the

\footnotetext{
${ }^{*}$ Corresponding author. Tel.: +33-492-076-799; Fax.: +33-492076-754

Email address: wilfried.blanc@unice.fr (W. Blanc)
}

Preprint submitted to J. Non Cryst. Solids divalent metal is also to prevent the clustering of $\mathrm{Er}^{3+}$ in phosphate phases as shown for similar samples in [7]. In these samples, the spectroscopic behaviour of $\mathrm{Er}^{3+}$ ions depends on the concentration of the alkaline-earth ions [8]. To explain these modifications, we study, in this article, the local order around $E r^{3+}$ by Extended Xray Absorption Spectroscopy (EXAFS) which permits to cast a link between local geometry and optical response. EXAFS at the $E r-L_{I I I}$ edge has already revealed to be effective in the description of the site of $\mathrm{Er}^{3+}$ [7] and $\mathrm{Yb}^{3+}$ [2] in optical fibre preforms with nanoparticles obtained by phase separation. It revealed a marked affinity between the RE and phosphate phases.

\section{Experimental}

\subsection{Sample preparation}

Preforms were fabricated by the conventional MVCD technique [9]. The so-called 'solution doping technique' [10] was applied to incorporate magnesium and erbium ions: the core porous layer, doped with $\mathrm{GeO}_{2}$ and $\mathrm{P}_{2} \mathrm{O}_{5}$, is soaked with an alcoholic solution of $\mathrm{ErCl}_{3}: 6 \mathrm{H}_{2} \mathrm{O}$ and $\mathrm{MgCl}_{2}: 6 \mathrm{H}_{2} \mathrm{O}$ of desired concentrations. After drying of the solvent, the core layer is sintered down to a dense glass layer. Then the tube is collapsed into a solid rod, referred to as preform, at an elevated temperature higher than $1800^{\circ} \mathrm{C}$. Preforms are stretched into $125-\mu \mathrm{m}$ fibres using a drawing tower at

September 16, 2013 


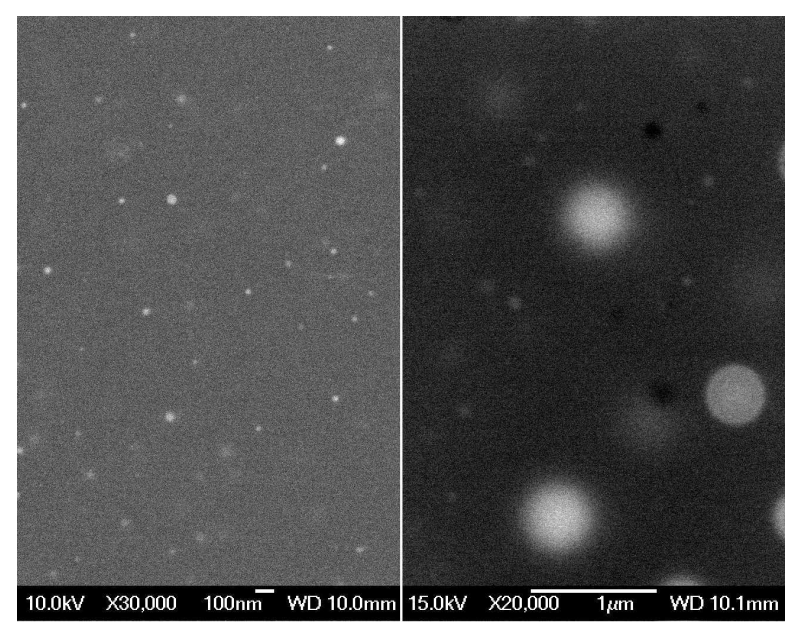

Figure 1: SEM pictures of Mg-0.1 (left) and Mg-1.5 (right) preforms.

temperatures higher than $2000{ }^{\circ} \mathrm{C}$ under otherwise normal conditions. Here we report on samples labeled as $\mathrm{Mg}-\mathrm{X}$ doped with solutions containing $\mathrm{X}=0,0.1,0.3$, $0.5,0.7,1$ and $1.5 \mathrm{~mol} / \mathrm{l}$ of $\mathrm{MgCl}_{2}$ salts. To investigate the role of phosphorus, two samples were prepared without this element and are labeled $\mathrm{Mg}-\mathrm{XnoP}$. Preform compositions were estimated from Energy Dispersive X-Ray measurements $\left(160 \times 130 \mu m^{2}\right.$ scanned area in the core) and Electron Probe Microanalyses. It was found that $\mathrm{GeO}_{2}$ and $\mathrm{P}_{2} \mathrm{O}_{5}$ mean concentrations are $0.8 \mathrm{~mol} \%$ and $0.4 \mathrm{~mol} \%$, respectively. $\mathrm{MgO}$ concentration increases from 0.1 (Mg-0.1) to $5.5 \mathrm{~mol} \%$ (Mg-1.5). Doping with $\mathrm{Mg}$ leads to the formation of nanoparticles in the core. SEM pictures for the Mg-0.1 and Mg-1.5 samples are presented in Fig.1. As previously observed, the mean size of the nanoparticles increases with $\mathrm{Mg}$ concentration [8]. It is about $50 \mathrm{~nm}$ in $\mathrm{Mg}-0.1$ up to hundreds of $\mathrm{nm}$ in $\mathrm{Mg}-1.5$. Optical losses induced by the NP have been discussed in a previous paper [8]. The erbium concentration of $0.01 \mathrm{~mol} / 1$ was kept constant in the doping solution and the erbium ion concentration in samples was previously estimated to be $200 \mathrm{ppm}$ [8].

\subsection{Photoluminescence}

Emission spectra of $\mathrm{Mg}$-doped core of the preforms were recorded at room temperature. The beam from a continuous $980 \mathrm{~nm}, 250-\mathrm{mW}$ fiber-coupled laser diode was coupled into the tested preform through a singlemode fiber-coupler. The $1550 \mathrm{~nm}$ fluorescence was collected from the second coupler arm and it was directed, through an isolator, to an optical spectrum analyzer (Anritsu MS9701C). The resolution of the OSA was $1 \mathrm{~nm}$. Emission spectra reported in Fig. 2 are averaged on twenty sweeps and the signal is smoothed on

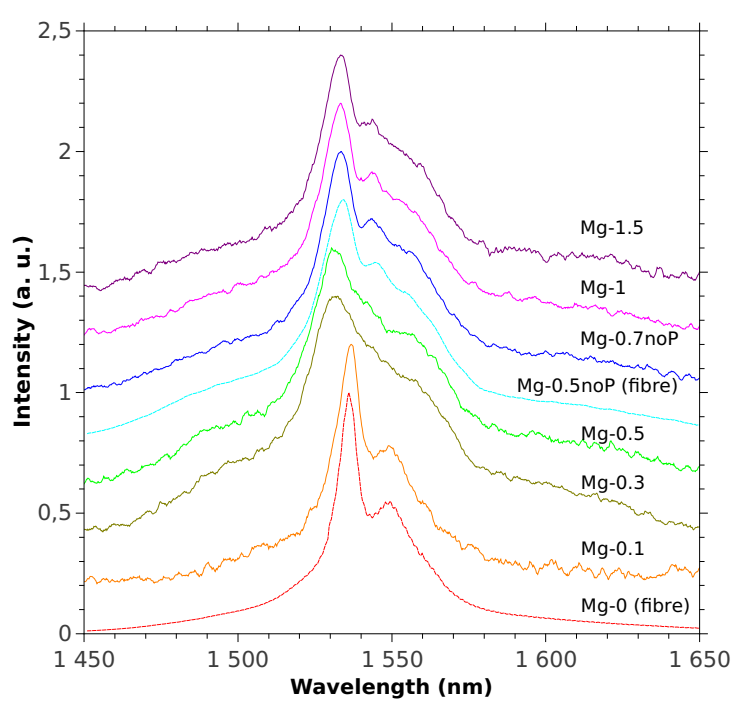

Figure 2: Emission spectra of Mg-doped preforms (continuous lines) and fibres (dashed lines) recorded at room temperature. Excitation wavelength is $980 \mathrm{~nm}$. Each spectrum is shifted vertically by 0.2 .

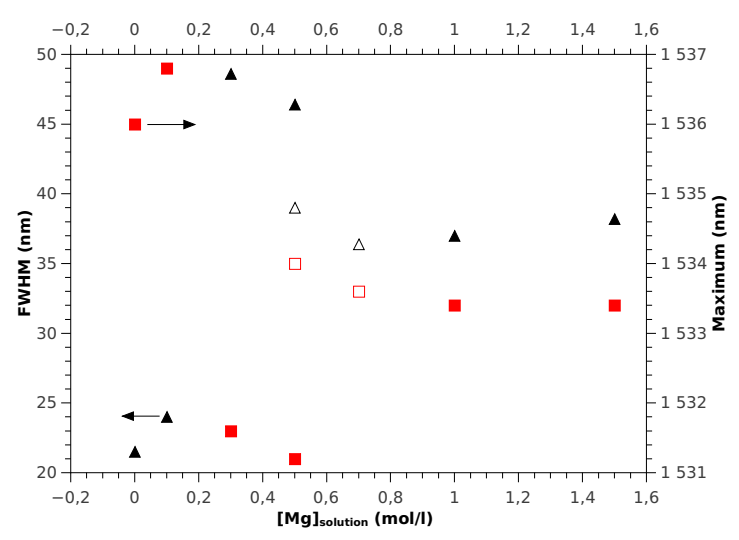

Figure 3: FWHM (triangles) and wavelength of the maximum of fluorescence intensity (squares) vs Mg concentration. Open symbols are related to the samples without $\mathrm{P}$. 
eleven points. FWHM and wavelength of the maximum of fluorescence intensity are reported in Fig.3.

\subsection{X-ray Absorption Spectroscopy}

XAS measurements have been carried out at the GILDA-CRG beamline BM08 at the European Synchrotron Radiation Facility [11]. The monochromator was equipped with a pair of $\mathrm{Si}(311)$ crystals and was run in dynamical (horizontal) focusing mode [12]. The harmonic rejection as well as the vertical focusing was achieved by using a pair of Pd-coated mirrors with a cutoff energy $E_{\text {cutoff }}=18 \mathrm{keV}$. This optical arrangement permitted to obtain a focal spot of about $200 \times 200 \mu \mathrm{m}$ on the sample location, small enough to probe the core of the preform. The absorption coefficient was measured in fluorescence mode by using an energy resolving detector (12-elements array High Purity Ge). The spectra are shown in Fig.4 whereas the related Fourier Transforms are shown in Fig.5.

The structural model used for the quantitative data analysis is the same used in previous literature for this class of systems $[13,14,15]$ : a $\mathrm{RE}$ ion linked to a $\mathrm{SiO}_{4}$ tetradedron with a well defined Er-O distance and Er$\mathrm{O}-\mathrm{Si}$ bond angle. Here we note that, due to the similar backscattering amplitude and phase of $\mathrm{Si}, \mathrm{P}$ and $\mathrm{Mg}$ it is not possible to distinguish these three atoms in the second coordination shell. The data analysis was carried out with the ATHENA and ARTEMIS [16] codes and the theoretical XAS paths were generated with the Feff8.10 code [17] starting from the $\mathrm{Er}_{2} \mathrm{Si}_{2} \mathrm{O}_{7}$ crystal structure [18]. The EXAFS signal was modelized by using the main scattering signals originating from the Er$\mathrm{O}-\mathrm{Si}$ triangular configuration as thoroughly discussed in [14]. The Debye Waller factor of the second shell was fixed to $0.002 \AA^{2}$ whereas the number of oxygen first neighbors was linked to the Er-O bond length by using the data from the Bond Valence Method (BVM, [19]). BVM has been suggested in literature as an effective method in XAS data analysis to reduce the correlation between fit parameters [20]. By using the parameters published in [21] the relationship between the number of $\mathrm{O}$ atoms $N_{O}$ and the Er-O bond length $R_{E r-O}$ can be approximated as :

$$
N_{O} \approx 63.343-67.499 \times R_{E r-O}+18.695 \times R_{E r-O}^{2}
$$

The results of the quantitative analysis are shown in Table1.

\section{Results and Discussion}

From Fig.2 and Fig.3, $E r^{3+}$ fluorescence properties can be separated into three $\mathrm{Mg}$-concentration domains.

\begin{tabular}{|c|c|c|c|c|}
\hline Sample & $N_{O}$ & $R_{E r-O}(\AA)$ & $\sigma_{O}^{2}\left(\AA^{2}\right)$ & $R_{E r-S i}(\AA)$ \\
\hline $\mathrm{Mg}-0$ & 4 & $2.30(2)$ & $0.01(5)$ & - \\
& 4 & $2.37(2)$ & $0.01(5)$ & - \\
$\mathrm{Mg}-0.1$ & $7(1)$ & $2.31(6)$ & $0.013(6)$ & $3.7(2)$ \\
$\mathrm{Mg}-0.3$ & $6.9(7)$ & $2.30(4)$ & $0.013(4)$ & $3.7(1)$ \\
$\mathrm{Mg}-0.5$ & $6.9(7)$ & $2.29(4)$ & $0.011(4)$ & $3.7(1)$ \\
$\mathrm{Mg}-0.5 \mathrm{noP}$ & $6(1)$ & $2.24(3)$ & $0.006(1)$ & $3.6(1)$ \\
$\mathrm{Mg}-0.7 \mathrm{noP}$ & $7(1)$ & $2.28(6)$ & $0.014(6)$ & $3.6(2)$ \\
$\mathrm{Mg}-1$ & $6.3(7)$ & $2.26(4)$ & $0.012(4)$ & $3.6(1)$ \\
$\mathrm{Mg}-1.5$ & $6.2(7)$ & $2.26(4)$ & $0.012(4)$ & $3.6(1)$ \\
\hline
\end{tabular}

Table 1: Results of the quantitative analysis of the EXAFS data. Sample $\mathrm{Mg}-0$ is fitted with a crystalline $\mathrm{ErPO}_{4}$ model.

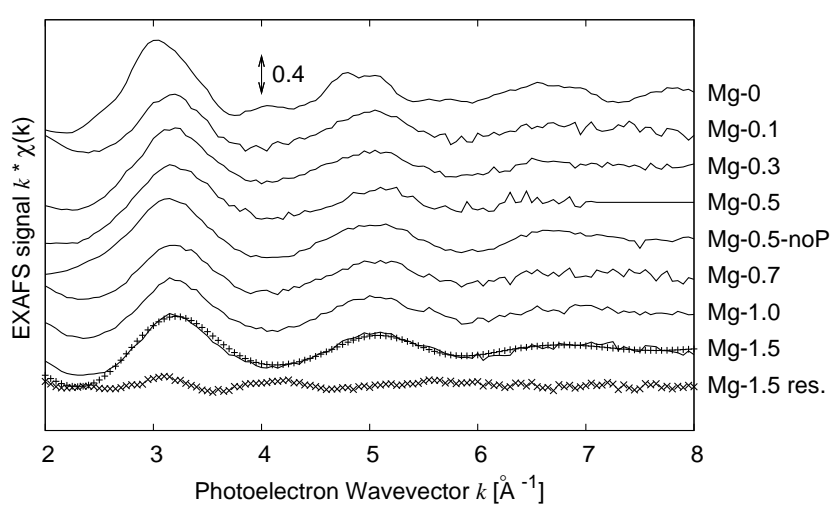

Figure 4: EXAFS spectra of the various Mg-doped samples (0.1-1.5) compared with a sample without divalent codopant $(\mathrm{Mg}-0)$. For $\mathrm{Mg}$ 1.5 also the fit is shown $(+)$ with the residual $(\times)$.

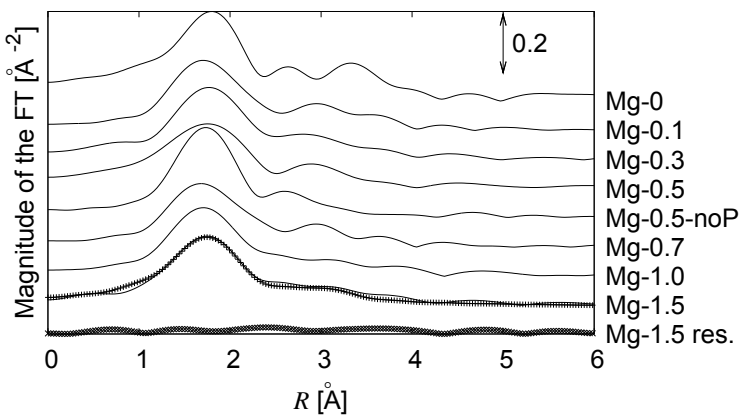

Figure 5: Fourier Transforms of the spectra shown in Fig.4. For Mg1.5 also the fit is shown $(+)$ with the residual $(\times)$. 
At low concentration (Mg-0 and $\mathrm{Mg}-0.1)$, FWHM is about $20-25 \mathrm{~nm}$ and the main peak position is at 1536 $\mathrm{nm}$. These values correspond to those measured in a Pdoped silica fiber [22]. For intermediate $\mathrm{Mg}$ concentration (Mg-0.3 and Mg-0.5), FWHM increases up to 45$50 \mathrm{~nm}$, the peak position shifts to shorter wavelengths and the spectrum appears poorly structured. As particle sizes increase compare to previous samples, one may expect that the fluorescence spectrum could be influenced by reabsorption effect. However, this effect would shift peak position to longer wavelengths. For the highest $\mathrm{Mg}$ concentration (Mg-1 and Mg-1.5), FWHM and peak position values are $35-40 \mathrm{~nm}$ and $1533 \mathrm{~nm}$, respectively, whereas structures appear in the long wavelength side of the line. These two values are close to those reported for samples without $\mathrm{P}$ (open symbols in Fig.3). They can also be compared with values reported for alumino-germano-silicate fibre (type II in [22]): FWHM and peak position are $40 \mathrm{~nm}$ and 1533 $\mathrm{nm}$, respectively.

The EXAFS spectra (Fig.4) show less differences respect to optical fluorescence with the exception of $\mathrm{Mg}$ 0 sample which contains more oscillating components than the others as also confirmed by the Fourier Transform (FT) (Fig.5). As previously reported for this sample [7], the additional signals above the first coordination shells are due to the formation of nuclei with the $\mathrm{ErPO}_{4}$ structure. This P-cage effect has been already reported [23]. However, the fluorescence spectrum of $\mathrm{Mg}-0$ does not present any features of crystalline phase [24] suggesting that this phase is not spatially extended and consist of only a few coordination shells (around 4-5 $\AA$ ). The Mg-doped samples exhibit a dominant oscillation due to a Er-O coordination shell (Fig. 4). The FT confirms this idea as it shows only a dominant main peak at about $1.8 \AA$ (Fig. 5). This situation is typical of rare-earth ions embedded in a glassy matrix. By increasing $\mathrm{Mg}$ concentration, $R_{E r-O}$ smoothly decreases from 2.31 down to $2.26 \AA$ and the resulting $N_{0}$ decreases from 7 to 6 (Table 1).

Both fluorescence and EXAFS measurements demonstrate that $\mathrm{Er}^{3+}$ ions experience different environements with $\mathrm{Mg}$ concentration. In the $\mathrm{Mg}-\mathrm{O}$ sample, a well organised solvation shell is formed by $\mathrm{P}$ around $\mathrm{Er}$ as already observed with this $\mathrm{RE}[23,24]$ and $\mathrm{Yb}$ [2]. In the $\mathrm{Mg}$-doped samples, the composition of the environment can not be determined exactly from EXAFS measurements as $\mathrm{Mg}$, Si and $\mathrm{P}$ can not be distinguished with EXAFS analyses. However, we have reported that, in $\mathrm{Mg}$-doped samples, Er ions are located in the nanoparticles which contain also $\mathrm{P}$ and $\mathrm{Mg}$ ions [25]. Concentrations of these three elements in the NP are expected to be higher than the mean concentrations reported in 2.1. Then, Mg-0.3 and Mg-0.5 results could be explained by assuming a P-rich and/or well polymerized environment. Indeed, the degree of glass polymerization has been found to be correlated to the RE-O bond length in phosphate glasses [26]. In the case of ultraphosphate glasses, $N_{0}=7.3$ and $R_{E r-O}=2.29 \AA$ have been reported by [26], in accordance with $\mathrm{Mg}$-intermediate concentration results. Moreover, FWHM of $\mathrm{Er}^{3+}$ emission bands in phosphate glasses is usually larger compare to those reported in silicate [27]. When $\mathrm{Mg}$ concentration increases, phosphate network tends to depolymerize [28, 29]. In the less polymerized metaphosphate glass, $N_{0}=6.3$ and $R_{E r-O}=2.23 \AA$ [26], as observed for the highest $\mathrm{Mg}$ concentration. FWHM tends also to decrease when $\mathrm{Mg}$ is added to a phosphate glass [30]. However, for the highest $\mathrm{Mg}$ concentrations, the presence of $\mathrm{P}$ in the local environment of Er can not be asserted from these measurements as same characteristics are obtained in P-doped samples (Mg-1 and $\mathrm{Mg}-1.5)$ and P-free samples (Mg-0.5noP and $\mathrm{Mg}-0.7 \mathrm{noP})$.

\section{Conclusion}

In this article we report on the modification of the erbium ions environment by changing $\mathrm{Mg}$ concentration. Different environments are identified by comparing fluorescence and EXAFS measurements. These changes are attributed to the depolymerization of the phosphate network. These results gain insight into the tayloring of luminescence properties of RE-doped optical fibres.

\section{Acknowledgements}

Authors greatly acknowledge Michèle Ude and Stanislaw Trzesien (LPMC) for the preparation of the preforms, Olivier Tottereau (Univ. Nice Sophia Antipolis, CNRS, CRHEA, UPR 10, Valbonne, France) for SEM/EDX measurements and Ivan Kasik for EPMA measurements realized at the Institute of Photonics and Electronics of the Academy of Sciences of the Czech Republic. GILDA is a project jointly financed by CNR and INFN.

\section{References}

[1] B. Samson, P. Tick, N. Borrelli, Optics letters 26 (2001) 145147.

[2] C. Oppo, R. Corpino, P. Ricci, M. Paul, S. Das, M. Pal, S. Bhadra, S. Yoo, M. Kalita, A. Boyland, J. Sahu, P. Ghigna, F. dAcapito, Optical Materials 34 (2012) 660 - 664. 
[3] J. Thomas, M. Myara, L. Troussellier, E. Burov, A. Pastouret, D. Boivin, G. Mélin, O. Gilard, M. Sotom, P. Signoret, Optics express 20 (2012) 2435-2444.

[4] W. Blanc, B. Dussardier, G. Monnom, R. Peretti, A.-M. Jurdyc, B. Jacquier, M. Foret, A. Roberts, Appl. Opt. 48 (2009) G119G124.

[5] W. Blanc, B. Dussardier, M. C. Paul, Glass Technology - European Journal of Glass Science and Technology Part A 50 (2009) 79-81.

[6] W. Blanc, V. Mauroy, B. Dussardier, Int. J. of Nanotechnology 9 (2012) 480-487.

[7] F. dAcapito, C. Maurizio, M. Paul, T. S. Lee, W. Blanc, B. Dussardier, Materials Science and Engineering: B 146 (2008) 167 170.

[8] W. Blanc, V. Mauroy, L. Nguyen, B. Shivakiran Bhaktha, P. Sebbah, B. P. Pal, B. Dussardier, Journal of the American Ceramic Society 94 (2011) 2315-2318.

[9] H. P. J.B. Mac Chesney, P.B. Oapos Connor, Proc IEEE 62 (1974) 1280-1281.

[10] S. P. J.E. Townsend, D. Payne, Elect. Lett. 23 (1987) 329-331.

[11] F. D'Acapito, S. Colonna, S. Pascarelli, G. Antonioli, A. Balerna, A. Bazzini, F. Boscherini, F. Campolungo, G. Chini, G. Dalba, I. Davoli, P. Fornasini, R. Graziola, G. Licheri, C. Meneghini, F. Rocca, L. Sangiorgio, V. Sciarra, V. Tullio, S. Mobilio, ESRF Newsletter 30 (1998) 42.

[12] S. Pascarelli, F. Boscherini, F. D’Acapito, J. Hrdy, C. Meneghini, S. Mobilio, J. Synchrotron Rad. 3 (1996) 147.

[13] F. D’Acapito, S. Mobilio, P. Gastaldo, D. Barbier, L. F. Santos, O. Martins, R. M. Almeida, J. Non-Cryst. Solids 293-295 (2001) $118-124$.

[14] F. D'Acapito, S. Mobilio, S. Scalese, A. Terrasi, G. Franzò, F. Priolo, Phys. Rev. B 69 (2004) 153310.

[15] F. D'Acapito, S. Mobilio, P. Bruno, D. Barbier, J. Philipsen, J. Appl. Phys. 90 (2001) 265

[16] B. Ravel, M. Newville, J. Synchrotron Rad. 12 (2005) 537-541.

[17] J. J. Rehr, R. C. Albers, Rev. Mod. Phys. 72 (2000) 621-654.

[18] Y. Smolin, Y. Shepelev, Acta Crystall. B 26 (1970) 484.

[19] I. D. Brown, D. Altermatt, Acta Crystallographica Section B 41 (1985) 244-247.

[20] M. Newville, Physica Scripta 2005 (2005) 159.

[21] I. D. Brown, 2011. Http://www.iucr.org/resources/data/datasets/bondvalence-parameters.

[22] E. Desurvire, Erbium-doped fiber amplifiers: Principles and applications, Wiley (New York), 1994.

[23] A. Saitoh, S. Matsuishi, C. Se-Weon, J. Nishii, M. Oto, M. Hirano, H. Hosono, J. Phys. Chem. B 110 (2006) 7617-7620.

[24] R. Peretti, A. Jurdyc, B. Jacquier, W. Blanc, B. Dussardier, Optical Materials 33 (2011) 835-838.

[25] W. Blanc, C. Guillermier, B. Dussardier, Opt. Mater. Express 2 (2012) 1504-1510.

[26] M. Karabulut, E. Metwalli, A. Wittenauer, R. Brow, G. Marasinghe, C. Booth, J. Bucher, D. Shuh, Journal of Non-Crystalline Solids 351 (2005) $795-801$.

[27] S. Jiang, M. Myers, N. Peyghambarian, Journal of NonCrystalline Solids 239 (1998) $143-148$.

[28] G. Walter, U. Hoppe, T. Baade, R. Kranold, D. Stachel, Journal of non-crystalline solids 217 (1997) 299-307.

[29] I. Wacławska, M. Szumera, Journal of thermal analysis and calorimetry 84 (2006) 185-190.

[30] S. Jiang, T. Luo, B.-C. Hwang, F. Smekatala, K. Seneschal, J. Lucas, N. Peyghambarian, Journal of Non-Crystalline Solids 263264 (2000) 364-368. 